\title{
Temperature constraints on phenotypic plasticity explain biogeographic patterns in predator trophic morphology
}

\author{
Ashley K. Baldridge ${ }^{1,2}$, L. David Smith ${ }^{1, *}$ \\ ${ }^{1}$ Department of Biological Sciences, Smith College, Northampton, Massachusetts 01063, USA \\ ${ }^{2}$ Present address: Department of Biological Sciences, University of Notre Dame, Notre Dame, Indiana 46556, USA
}

\begin{abstract}
Phenotypic plasticity in feeding structures allows invasive predators to adjust to variation in prey defenses, but the abiotic milieu may constrain the extent or rate of the response. In the northwest Atlantic Ocean, the introduced European green crab Carcinus maenas encounters latitudinal differences in shell thickness of its snail prey, Littorina obtusata, and water temperature. To determine whether claw size in this heterochelous species responds to broad-scale differences in prey armor or water temperature, we reared C. maenas on a diet of thick- or thin-shelled L. obtusata at 16 or $10^{\circ} \mathrm{C}$. At the higher temperature, crusher claw size increased significantly more at the molt relative to carapace width increase for crabs raised on the thick-shelled rather than thin-shelled diet. The lower temperature inhibited trophic responses in the crusher claw by reducing foraging performance on thick-shelled snails, and lower temperature also prolonged the molt interval. Cutter claw growth showed no diet effect at either temperature. Non-additive responses to multiple cues highlight the importance of testing for phenotypic plasticity over a range of environmental backgrounds and help explain post-invasion biogeographic patterns between an introduced predator and its prey.
\end{abstract}

KEY WORDS: Phenotypic plasticity - Biological invasions · Biogeography · Trophic plasticity · Carcinus maenas $\cdot$ Littorina obtusata $\cdot$ Water temperature $\cdot$ Ecological arms race

Resale or republication not permitted without written consent of the publisher

\section{INTRODUCTION}

Successful biological invaders must adjust to new environments, and phenotypic plasticity (environmentally induced change in a character) provides a means for within-generation response (Agrawal 2001). In instances where the invader is a predator, induced changes in trophic (i.e. feeding) structures may permit the invader to track variation in prey characteristics in time or space. Studies, conducted primarily in noninvaded systems, have shown that organisms from diverse taxonomic groups can modify their feeding structures in response to diet (e.g. ciliates, Kopp \& Tollrian 2003; arthropods, Bernays 1986; amphibians, Kishida et al. 2006). These morphological changes were either hypothesized or demonstrated to improve predator foraging success and, thus, are considered examples of adaptive phenotypic plasticity (Robinson \& Parsons 2002). The extent to which diet-induced plasticity promotes colonization, facilitates spread, or generates post-invasion spatiotemporal patterns following predator introductions, however, is not generally well understood.

As an introduced species expands its range, it will probably be confronted by an array of biotic and abiotic cues. To date, most studies on plasticity have tested for phenotypic responses to single localized cues without considering broad-scale spatial variation in the background milieu (Miner et al. 2005). Background stimuli, such as photoperiod, salinity or temperature, however, could modify an organism's ability to respond to other cues. For example, ambient tem- 
perature varies spatially with latitude, elevation and depth. Because temperature directly affects metabolism, feeding ability and growth rates (Hartnoll 2001, Petry et al. 2007), geographic variation in temperature could have profound effects on the expression of induced traits (Conover \& Schultz 1995, Trussell 2000). Predicting the consequences of a predator introduction requires an understanding of how the abiotic background influences both the magnitude and rate of induced responses over the invader's range.

The European green crab Carcinus maenas (L.) is a model organism used to test for environmental influences on trophic structure following an invasion. Over the past 2 centuries, C. maenas has successfully broadened its range worldwide (Grosholz \& Ruiz 1996). The ability of $C$. maenas to tolerate a wide range of temperatures and salinities and its facility as a prey generalist (Behrens Yamada 2001) may have contributed to its success as an invader. Its effectiveness as a predator on hard-shelled prey is due, in part, to the power and dexterity of its dimorphic claws. Carcinus maenas uses its larger and stronger crusher claw to breach prey armor and its smaller, but more dexterous, cutter claw to manipulate items (Schenk \& Wainwright 2001). Claw size correlates positively with closing force in crabs (Taylor 2000) and, thus, is probably an important determinant of foraging success for C. maenas (Lee 1993).

The invasion of Carcinus maenas into the western Atlantic Ocean in the early 19th century (Carlton \& Cohen 2003) provides an opportunity to test whether (1) geographic variation in prey defenses induces changes in claw size, (2) latitudinal differences in water temperature modify the trophic response, and (3) their combined effect can explain biogeographic patterns in trophic morphology. In rocky intertidal habitats in the Gulf of Maine, sizes of C. maenas crusher claws have diverged in the last century such that green crabs in the southern Gulf of Maine have relatively larger crusher claws than those in the north (Smith 2004, Edgell \& Rochette 2007). This pattern mirrors a cline in shell thickness and breakage resistance in a native species of snail prey, Littorina obtusata (L.); i.e. thicker shelled, more resistant snails are found in the south rather than in the north (Trussell 2000). In contrast, cutter claws showed no geographic differences in relative size (Smith 2004). The correlation between crusher claw size and prey armor suggests an adaptive trophic response by the predator to its prey, but the causal mechanism (diet-induced plasticity, rapid selection on claw size) has not been established. If claw form is responsive to natural variation in shell thickness, we hypothesized that $C$. maenas fed thickshelled L. obtusata would increase their crusher claw size to a greater degree than would crabs fed thin- shelled snails, but that cutter claws would not differ in size.

A coincident latitudinal gradient in water temperature in the Gulf of Maine has the potential to modify diet-induced responses in claw size by altering a crab's metabolic demands, feeding performance, size increase at the molt or molting frequency. Peak summertime water temperatures in the northern regions of the Gulf of Maine are on average 6 to $7^{\circ} \mathrm{C}$ lower than in the southern regions (Trussell \& Smith 2000, L. D. Smith unpubl. data). Because crustaceans remodel their exoskeleton only in a brief interval after ecdysis while the cuticle is soft (Smith \& Palmer 1994), molting frequency ultimately governs the rate of plastic response in crabs. A priori, we predicted that colder temperatures would limit the phenotypic response of Carcinus maenas to diet by reducing foraging activity or lengthening intermolt period.

In this study, we tested experimentally for induced responses in trophic morphology of Carcinus maenas to latitudinal differences in shell defenses of Littorina obtusata and water temperature. Our results demonstrated non-additive ecophenotypic responses to diet and temperature that were claw-specific and suggest that phenotypic plasticity can explain observed biogeographic patterns in trophic morphology after an invasion. Our results also suggest that, as global warming continues, C. maenas will be released from temperature constraints on foraging along its northwestern Atlantic Ocean range and have greater effect as an invasive predator.

\section{MATERIALS AND METHODS}

Experimental design. To test the effects of prey shell thickness and water temperature on Carcinus maenas claw morphology and body growth, we reared juvenile male crabs on thick- or thin-shelled Littorina obtusata at high or low temperatures $\left(16\right.$ or $\left.10^{\circ} \mathrm{C}\right)$. All crabs were collected by hand from the low- to-mid intertidal zone of a moderately wave-protected rocky embayment (Haycock Harbor, South Trescott, Maine, USA) in the northern Gulf of Maine on 22 June 2005. We selected right-handed crabs with both claws intact and no visible signs of claw regeneration. We collected a size range (shell length 3 to $14 \mathrm{~mm}$ ) of L. obtusata monthly from June to December 2005 in habitat similar to that described for C. maenas.

Treatment levels for prey shell thickness (i.e. diet) and temperature reflected the natural range of variation between sites in the southern and northern Gulf of Maine. Thick-shelled snails were collected in the southern Gulf of Maine at sites in eastern Massachusetts (Nahant to Rockport) and later in Stonington, Connecticut. Thin- 
shelled snails were collected in the northern Gulf of Maine at sites along the northeastern coast of Maine (South Lubec). Shell thicknesses differed between southern and northern sites by approximately $30 \%$ after adjusting for shell length (1-way ANCOVA, $F_{2,94}=13.02$, $\mathrm{p}<0.001)$. The high temperature $\left(16^{\circ} \mathrm{C}\right)$ and low temperature $\left(10^{\circ} \mathrm{C}\right)$ treatments represented average daily peak summertime water temperatures recorded, respectively, at Manchester-by-the-Sea, Massachusetts, and South Lubec, Maine, in 2004 (L. D. Smith unpubl. data). Temperatures at each site were measured using submersible data loggers (Onset Computer).

The experiment was conducted at Smith College in Northampton, Massachusetts. Crabs were held in 2 temperature- and light-controlled (12:12 h light:dark) incubators (Percival, Model I36LL). Each crab was maintained in a separate, clear, polystyrene jar $(11 \mathrm{~cm}$ diameter $\times 9.5 \mathrm{~cm}$ height) that contained approximately $1 \mathrm{~cm}$ of white sand and $0.7 \mathrm{l}$ of artificial seawater (Crystal Sea ${ }^{\circledR}$, Aquatic Ecosystems). A single air stone aerated each jar, and seawater was mixed to a salinity of 31 to 33 ppt. Thick- and thin-shelled snails were kept in separate $10^{\circ} \mathrm{C}$ aquaria for use in the experiment and fed brown algae Ascophyllum nodosum (L.).

We assigned 23 crabs to each of the 4 diet $\times$ temperature treatment combinations, making sure there was a similar size distribution among the treatment groups (carapace width $[\mathrm{CW}$ ] range $=13.6$ to $38.1 \mathrm{~mm}$, mean $\mathrm{CW} \pm 1 \mathrm{SD}=27.2 \pm 6.4 \mathrm{~mm}$ ) (Table 1). In several instances in each treatment combination, small female or left-handed crabs were mistakenly used instead of right-handed males, and these were eliminated from subsequent analyses. Each diet treatment, however, remained approximately equally represented in each temperature treatment (Table 1).

Crabs molted twice in captivity. Each exoskeleton chronicled the effects of diet and temperature experienced in the preceding molt interval (Fig. 1). For convenience, we named each exoskeleton for the diet and temperature conditions from which it originated (Field, Equilibration, Treatment; described in the next section).
Experimental protocol. Beginning 1 July 2005, all crabs were acclimated to their treatment temperature over $1 \mathrm{wk}$. During the first molt interval in captivity, we reared all crabs in both temperature treatments on a common diet of crushed Littorina obtusata (shell length [SL] > $12 \mathrm{~mm}$ ) administered 3 times each week. The number of crushed snails given to each crab increased in relation to its carapace width (2 snails for CW $<23 \mathrm{~mm}, 3$ snails for CW 23 to $30 \mathrm{~mm}$, 4 snails for $\mathrm{CW}>30 \mathrm{~mm}$ ). Every 10 to $20 \mathrm{~d}$ throughout the experiment, we measured the wet weight of each crab after blotting with a paper towel.

The first molt in captivity generated a shed Field exoskeleton and the new Equilibration exoskeleton that housed the crab. The Field exoskeleton reflected environmental conditions the crab had experienced in the wild. The Equilibration exoskeleton reflected a variable amount of exposure (depending on the length of time before the first molt in captivity) to field and equilibration (i.e. common diet and high or low temperature) conditions (Fig. 1), and the change in claw size between the Field and Equilibration exoskeletons measured the associated trophic response.

During the second molt interval in captivity, each crab was kept at its same temperature treatment, but started on its respective diet treatment, which consisted of intact thick- or thin-shelled Littorina obtusata

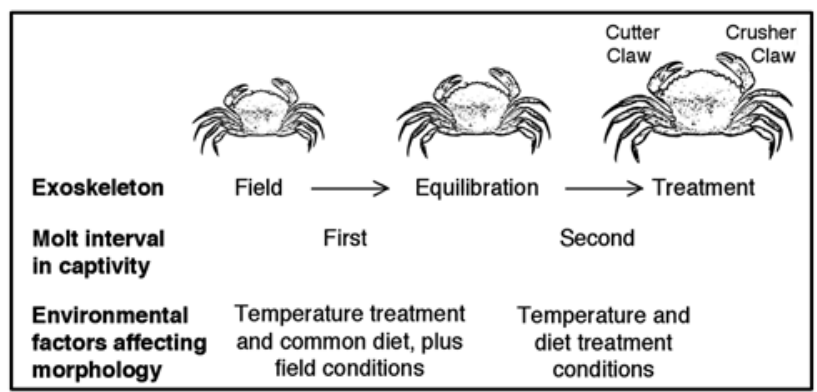

Fig. 1. Carcinus maenas. Origins of exoskeletons and environmental factors affecting morphology during 2 molt intervals in captivity. Crusher and cutter claws indicated

Table 1. Carcinus maenas. Sample sizes for each temperature (high or low) and diet (thick or thin shelled) treatment combination and mean carapace widths of intact male crabs according to origin of the molt in the experiment. Values in bold indicate the number of crabs that died during the molt interval. Values in italics indicate the number that did not molt by the end of the experiment

\begin{tabular}{|c|c|c|c|c|c|c|c|}
\hline \multirow{3}{*}{ Origin of molt } & \multirow[t]{3}{*}{ Total } & \multicolumn{4}{|c|}{ No. of crabs } & \multirow{2}{*}{\multicolumn{2}{|c|}{$\begin{array}{c}\text { Carapace width } \\
(\mathrm{mm})\end{array}$}} \\
\hline & & Low ter & perature & High tem & perature & & \\
\hline & & Thick shelled & Thin shelled & Thick shelled & Thin shelled & Mean & SE \\
\hline Field & 76 & $17(\mathbf{1})$ & $21(\mathbf{1})$ & 19 (3) & 19 (1) & 27.15 & 0.74 \\
\hline Equilibration & 70 & $16(3,7)$ & $20(\mathbf{0}, 8)$ & $16(\mathbf{1}, 5)$ & $18(\mathbf{0}, 3)$ & 34.22 & 0.93 \\
\hline Treatment & 43 & 6 & 12 & 10 & 15 & 37.90 & 1.34 \\
\hline
\end{tabular}


scaled to the crab's carapace width (crab CW $<25 \mathrm{~mm}$, snail SL between 3 and $5 \mathrm{~mm}$; CW 25 to $35 \mathrm{~mm}$, SL 5 to $6 \mathrm{~mm}$; CW 35 to $40 \mathrm{~mm}$, SL 6 to $7 \mathrm{~mm}$; CW $>40 \mathrm{~mm}$, SL 7 to $8 \mathrm{~mm}$ ). Snail sizes were determined experimentally to fall within the range a given size Carcinus maenas could crush (E. Callaghan \& L. D. Smith unpubl. data). Initially, we gave each crab 3 snails per feeding, with 3 feedings each week, but shifted to 5 snails per feeding, twice each week to allow more undisturbed time for snail handling. After each feeding bout, we removed snails and shells from each jar, recorded the condition of each snail, changed the seawater and added new snails. The condition of each snail was scored as either 'intact' (shell undamaged, snail alive), 'chipped' (shell damaged, snail alive), 'chipped, probed' (shell damaged, snail removed and eaten), 'probed' (shell undamaged, snail eaten), or 'crushed' if the crab successfully breached the spire of the shell or peeled the shell back to the innermost whorl (in both cases, the snail was eaten).

To ensure that the crabs had sufficient calcium carbonate to complete ecdysis, we provided calcium supplements consisting of finely ground cuttlebone and ground krill cooked in egg whites. Starting in midNovember 2005, we modified the protocol slightly, increasing the temperature in each incubator by $2^{\circ} \mathrm{C}$ and supplementing the diet of all crabs with flesh of the mussel Mytilus edulis (L.) once per week.

After the second molt in captivity, the new exoskeleton of each crab reflected the effects of an entire molt interval on the diet (thick- or thin-shelled) and temperature (high or low) treatments (Fig. 1), and the change in claw size between the Equilibration and Treatment exoskeletons measured the associated trophic response. The experiment was ended in March 2006.

Specimen preservation and measurement. Shed exoskeletons were preserved in $70 \%$ ethyl alcohol and glycerin. Live crabs were sacrificed and then fixed in $10 \%$ formalin buffered with seawater and sodium borate before being transferred to $70 \%$ ethyl alcohol and glycerin. All specimen measurements $( \pm 0.01 \mathrm{~mm})$ were made using digital calipers. For all Carcinus maenas, we measured carapace width (distance between tips of the 5th anterior-lateral spines) and the maximum height and depth of the manus (i.e. the portion of the claw excluding the fingers). Manus length was measured as the distance from the midpoint of the line between the upper and lower condyle socket at the proximal end of the manus to the intersection of the ventral margin of the dactyl with the manus.

Experimental versus wild crab claw size. To assess whether experimentally induced responses in claw size were similar in magnitude to geographic differences observed in the Gulf of Maine, we compared relative claw sizes of experimental crabs with those of wild-caught crabs collected in field surveys (Baldridge 2006) in Massachusetts and Maine in 2005.

Statistical analysis. All analyses of experimental data were conducted using JMP 5.1 software. In cases where $\log _{10}$ transformation was not necessary to meet the assumptions of normality, homogeneity of variance or homogeneity of slopes (for analysis of covariance [ANCOVA]), analyses were performed using untransformed data. When $\log _{10}$ transformations were used, data were back-transformed for presentation.

We used claw height as a proxy of claw size because it is an accurate predictor of claw strength in Carcinus maenas (Lee 1993, Smith 2004). To assess change in claw height at the molt, we conducted a series of 2-way ANCOVA models with the difference in claw height between successive exoskeletons as the response variable and temperature and diet as fixed factors. We used the corresponding increase in carapace width as a covariate to assess the degree of claw growth relative to body growth. Crusher and cutter claw data were analyzed separately.

To assess the crushing performance of the crabs, we pooled data on snail condition for all crabs within each treatment combination and compared counts using a contingency table analysis. Snails scored as 'intact' and 'probed' were combined into a single 'Intact' category, 'chipped' and 'chipped-probed' snails were pooled into a single 'Chipped' category, and 'crushed' snails comprised the 'Crushed' category. Only data for crabs that reached their Treatment molt were included in the analysis. We calculated the average snail tissue mass (g) consumed per day for each crab. To determine the effects of diet and temperature on overall consumption, we conducted ANCOVA on $\log _{10}$ tissue consumption rate $\left(\mathrm{g} \mathrm{d}^{-1}\right)$ after adjusting for $\log _{10}$ crab body mass $(\mathrm{g})$.

To analyze the effects of temperature and diet treatments on body size increase at the molt (molt increment) and intermolt duration, we used 2-way ANCOVAs. In the case of molt increment, the increase in carapace width between the Equilibration and Treatment exoskeletons served as the response variable and the Equilibration carapace width was the covariate. For intermolt duration, the time (in days) of the second molt interval served as the response variable and the carapace width of the crab in its Equilibration exoskeleton was the covariate.

\section{RESULTS}

\section{Claw size responses to temperature and diet}

Neither the temperature treatment nor the common diet of crushed snails received during the first molt interval in captivity had a significant effect on in- 
Table 2. Carcinus maenas. Results of 2-way ANCOVAs testing the effects of temperature and diet on increase in cutter and crusher claw height between the Field and Equilibration exoskeletons, and the Equilibration and Treatment exoskeletons. Corresponding increase in carapace width $(\mathrm{CW})$ served as the covariate. Significant $p$-values $(p \leq 0.05)$ are denoted by *

\begin{tabular}{|c|c|c|c|c|c|c|c|c|}
\hline \multirow{2}{*}{ Source } & \multicolumn{4}{|c|}{ - Cutter claw } & \multicolumn{4}{|c|}{ - Crusher claw } \\
\hline & $\mathrm{df}$ & MS & $F$-ratio & $\mathrm{p}$ & $\mathrm{df}$ & MS & $F$-ratio & $\mathrm{p}$ \\
\hline \multicolumn{9}{|c|}{ Field to Equilibration } \\
\hline Temperature & 1 & 0.047 & 1.94 & 0.169 & 1 & 0.070 & 0.68 & 0.413 \\
\hline Diet & 1 & 0.001 & 0.04 & 0.851 & 1 & $<0.001$ & $<0.01$ & 0.965 \\
\hline Temperature $\times$ Diet & 1 & 0.009 & 0.37 & 0.550 & 1 & 0.044 & 0.43 & 0.513 \\
\hline CW increase & 1 & 13.191 & 539.06 & $<0.001^{*}$ & 1 & 30.835 & 298.56 & $<0.001^{*}$ \\
\hline Residual & 65 & 0.024 & & & 65 & 0.103 & & \\
\hline \multicolumn{9}{|c|}{ Equilibration to Treatment } \\
\hline Temperature & 1 & 0.295 & 15.03 & $<0.001^{*}$ & 1 & 0.447 & 5.47 & $0.025^{*}$ \\
\hline Diet & 1 & 0.021 & 1.05 & 0.312 & 1 & 0.895 & 10.94 & $0.002^{*}$ \\
\hline Temperature $\times$ Diet & 1 & 0.037 & 1.89 & 0.177 & 1 & 0.423 & 5.17 & $0.029^{*}$ \\
\hline CW increase & 1 & 14.739 & 750.13 & $<0.001^{*}$ & 1 & 33.853 & 413.97 & $<0.001^{*}$ \\
\hline Residual & 38 & 0.020 & & & 38 & 0.082 & & \\
\hline
\end{tabular}

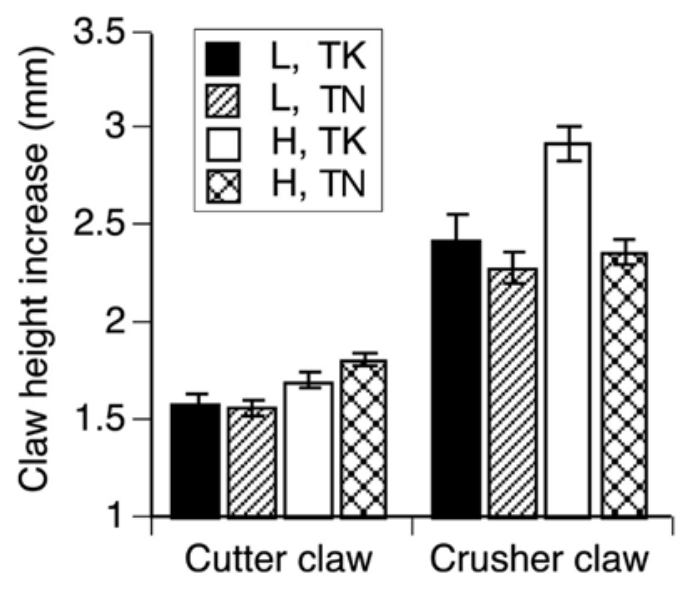

Fig. 2. Carcinus maenas. Effects of diet and temperature treatments on increase in cutter and crusher claw height at the second molt. Values represent least square means $( \pm 1 \mathrm{SE})$ from ANCOVA, adjusted for the corresponding increase in carapace width (mean $\pm 1 \mathrm{SE}, 7.29 \pm 0.31 \mathrm{~mm}$ ) between the Equilibration and Treatment exoskeletons. $\mathrm{L}=$ low temperature, $\mathrm{H}=$ high temperature, $\mathrm{TK}=$ thick-shelled snail diet, $\mathrm{TN}=$ thin-shelled snail diet

creases in height of cutter or crusher claws (Table 2). In contrast, cutter and crusher claws responded differently to temperature and diet treatments received during the second molt interval. Cutter claw heights increased significantly more for crabs reared at high rather than low temperature (2-way ANCOVA, p < $0.001)$, but diet had no significant effect on cutter claw increase ( $p=0.312$, Fig. 2, Table 2). Crusher claws, however, showed significant non-additive responses to temperature and diet (temperature $\times$ diet interaction, $\mathrm{p}=0.029$; Fig. 2, Table 2). At the low temperature, increases in crusher claw height did not differ between thick- and thin-shelled diets (1-way ANCOVA, $F_{1,15}=$ $0.54, p=0.47$; Fig. 2). In contrast, crusher claws of crabs reared on thick-shelled snails at the high temperature increased significantly more than did those of crabs raised on the thin-shelled diet $\left(F_{1,22}=27.79\right.$, $\mathrm{p}<0.001$; Fig. 2).

\section{Foraging performance}

Foraging performance differed significantly among treatment groups (contingency table analysis, $\chi^{2}=$ 3552.52, $\mathrm{p}<0.001$ ). Temperature had a stronger effect on the handling of thick-shelled snails than on thinshelled snails (Fig. 3). Crabs in the low temperature/ thick-shelled diet group crushed the lowest percentage of snails $(17 \%)$ and left the highest percentage intact $(30 \%)$. In contrast, crabs in the high temperature/thick-shelled diet group crushed $49 \%$ of snails offered and left approximately $9 \%$ intact. Crabs crushed the majority of thin-shelled snails at both temperatures (Fig. 3).

\section{Molt increment and intermolt duration}

Temperature and, to a lesser extent, diet affected carapace width increase and intermolt duration in the second molt interval. The average carapace width of crabs reared at the low temperature increased significantly more $(27.9 \pm 0.05 \%)$ than did that of crabs reared at high temperature $(21.1 \pm 0.04 \%)$ (2-way ANCOVA, $F_{1,38}=111.33, \mathrm{p}<0.001$; Fig. $4 \mathrm{~A}$ ). This differential growth resulted in larger absolute claw size for crabs in the low temperature treatment; however, the proportional change in crusher claw size was greater for crabs reared at high temperature after taking into account body size differences at Equilibration. Diet had no significant effect on molt increment $\left(F_{1,38}=\right.$ 


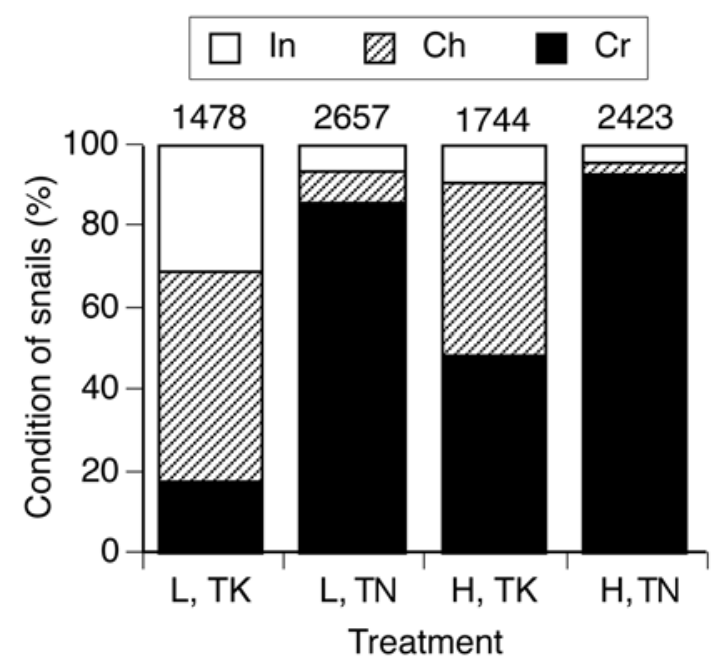

Fig. 3. Littorina obtusata. Condition of snail shells after crab foraging bouts expressed as the percentage of fate of all snails used in each temperature and diet treatment combination. 'Intact' (In) includes all undamaged shells, 'Chipped' (Ch) includes both chipped and chipped and probed shells, and 'Crushed' (Cr) includes all shells that were completely crushed. $\mathrm{L}=$ low temperature, $\mathrm{H}=$ high temperature, $\mathrm{TK}=$ thick-shelled snail diet, TN $=$ thin-shelled snail diet, number above bar $=$ total number of snails offered

0.05, $\mathrm{p}=0.826$; Fig. 4A). Crabs reared in the low temperature treatment took significantly longer to molt than did crabs at high temperature (2-way ANCOVA, $F_{1,38}=68.21, \mathrm{p}<0.001$; Fig. 4B). In addition, diet affected intermolt duration such that crabs raised on the thick-shelled snails took longer to molt than did crabs on the thin-shelled diet regardless of temperature $\left(F_{1,38}=5.53, \mathrm{p}=0.024 ;\right.$ Fig. $\left.4 \mathrm{~B}\right)$.

\section{Consumption rates}

At both temperatures, crabs on the thin-shelled diet consumed more snail flesh per day than did crabs on the thick-shelled diet (ANCOVA, covariate, $\log _{10}$ (crab mass); low temperature: $F_{1,14}=74.76, \mathrm{p}<0.001$; high temperature: $\left.F_{1,21}=15.06, \mathrm{p}<0.001\right)$. Controlling for diet, crabs in the high temperature treatment consumed more thick-shelled snail flesh per day than did crabs in the low temperature treatment $\left(F_{1,12}=21.32\right.$, $\mathrm{p}<0.001)$. In contrast, temperature had no significant effect on daily consumption of snail flesh for crabs on the thin-shelled diet $\left(F_{1,23}=0.83, \mathrm{p}=0.372\right)$.

\section{Experimental versus wild crab claw size}

The thick-shelled diet in our high temperature treatment generated crusher claws in our experimental
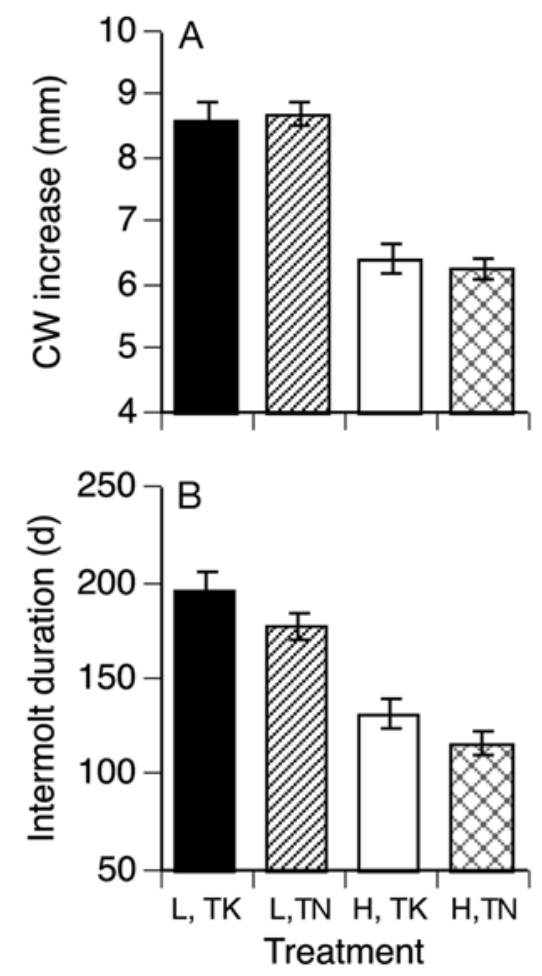

Fig. 4. Carcinus maenas. Effects of temperature and diet on (A) increase in carapace width (CW) between the Equilibration and Treatment exoskeletons and (B) duration of the second molt interval (days). Values are least square means $( \pm 1 \mathrm{SE})$ from ANCOVA adjusted for CW (mean $\pm 1 \mathrm{SE}, 30.61 \pm$ $1.08 \mathrm{~mm}$ ) of the Equilibration exoskeleton. $\mathrm{L}=$ low temperature, $\mathrm{H}=$ high temperature, $\mathrm{TK}=$ thick-shelled snail diet,

$\mathrm{TN}=$ thin-shelled snail diet

(northern source) crabs that were intermediate in claw height (relative to CW) to those in southern (Massachusetts) and northern (Maine) wild-caught crabs in the Gulf of Maine (Fig. 5). In contrast, crusher claw heights of crabs raised on thin-shelled snails at the high temperature did not differ from those of wildcaught crabs from the northern Gulf of Maine.

\section{DISCUSSION}

Crusher claw size of the invasive crab Carcinus maenas showed a temperature-dependent, use-induced response to natural variation in shell thickness of a native snail prey. This finding has ecological relevance because our treatments reflected the natural range of snail shell thicknesses and summertime water temperatures encountered by C. maenas in the Gulf of Maine. Our results suggest that claw plasticity enhances the foraging effectiveness of $C$. maenas in the warmer waters of the southern Gulf of Maine. In contrast, we predict that colder temperatures to the north will 
constrain morphological responses to prey defenses. The non-additive effects of diet and temperature on crusher claw plasticity highlight the need to test for ecophenotypic responses to particular cues of interest (e.g. prey, predator, nutrient) across relevant abiotic (or biotic) backgrounds (Miner et al. 2005).

Our findings extend earlier work by Smith \& Palmer (1994), who showed diet-induced effects in claw morphology of a homochelous crab, Cancer productus. In their experiment, crabs grown on fully shelled mussel prey developed larger and stronger claws than did those reared on unshelled mussels. The exoskeletal remodeling resulted from changes to the underlying claw muscle brought on by different amounts of exercise in the previous molt interval (Abby-Kalio \& Warner 1984, Taylor 2000). Our experiment demonstrated exercise-induced plasticity in a heterochelous crab to natural variation in prey shell thickness and, in one temperature-by-diet treatment combination, succeeded in amplifying the existing asymmetry between cutter and crusher claw size. Although crab claws are multi-functional structures, our findings emphasize the specialized roles of cutter and crusher claws in foraging. Cutter claws, which are designed for speed and dexterity (Schenk \& Wainwright 2001), did not respond to variation in prey armor. In contrast, crusher claws of heterochelous molluscivores possess features (e.g. larger size, greater mechanical advantage, molar-like

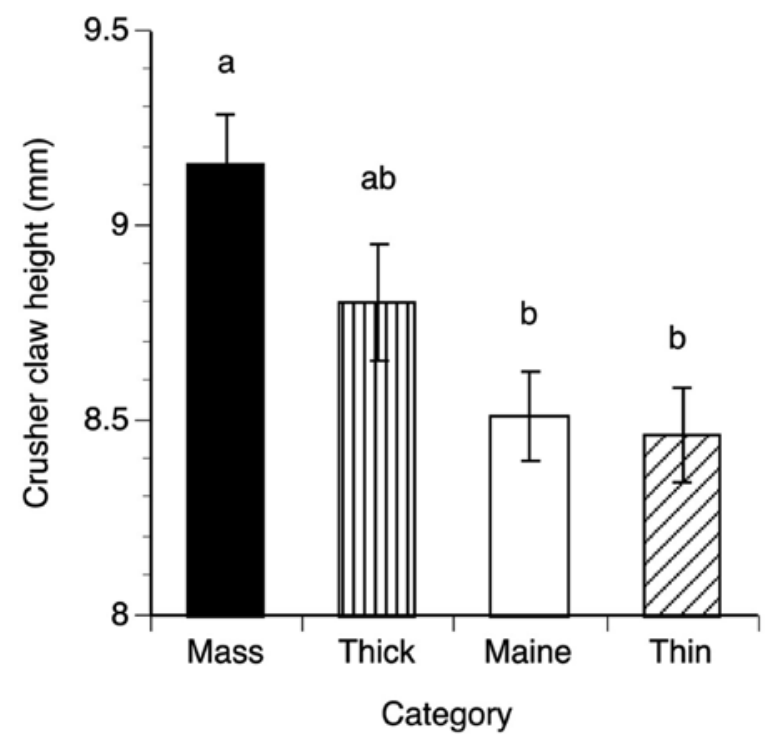

Fig. 5. Carcinus maenas. Final relative crusher claw size of high temperature treatment crabs raised on thick- or thinshelled snail diets compared with wild caught Massachusetts (Mass) and Maine population crabs. Values are least square means $( \pm 1 \mathrm{SE})$ from ANCOVA adjusted for carapace width (mean $\pm 1 \mathrm{SE}, 34.09 \pm 1.45 \mathrm{~mm}$ ). Groups not sharing the same letter above the bar are significantly different $(p<0.05)$ according to a Tukey's HSD test processes, longer muscle sarcomeres) designed to break hard-shelled prey (Behrens Yamada \& Boulding 1998, Schenk \& Wainwright 2001, Mitchell et al. 2003). Because a greater force is required to break thicker shelled molluscs (Trussell 2000), experimental crabs on the thick-shelled diet at the high temperature received a more rigorous exercise regimen than did crabs on the thin-shelled diet, and their crusher claws responded to the tougher diet by growing relatively larger in size.

The diet-induced difference in crusher claw height observed at the high temperature was absent at the low temperature (Fig. 2), and this non-additive response illustrates the importance of ambient temperature for trophic plasticity. In particular, low temperature constrained crusher claw response to more resistant prey in our experiment. Thus, while experimental crabs manipulated a majority of the thick-shelled snails offered at both temperatures, they crushed a considerably lower proportion of thick-shelled snails at the low temperature compared with the high temperature (Fig. 3). Crabs use a range of techniques (e.g. probing, peeling, chipping) to gain access to prey (Hughes \& Elner 1979, Moody \& Steneck 1993), but shell crushing is usually the first method attempted and the only one likely to significantly alter muscle properties. Our results suggest that the level of exercise received by crusher claw closer muscles of crabs on the thick-shelled diet at the low temperature was not sufficient to generate a response in trophic morphology.

Temperature could influence crushing performance and, thus, the potential for trophic response in a variety of ways. Carcinus maenas exhibits reduced feeding rates at lower temperature compared with higher temperatures $\left(10\right.$ vs. $17^{\circ} \mathrm{C}$, Wallace $1973 ; 10$ vs. $24^{\circ} \mathrm{C}$, Elner 1980). Both Wallace (1973) and Elner (1980) suggested that colder temperature might have lowered metabolic demands and, thus, reduced the need for food. Low temperature, however, did not suppress foraging rates on thin-shelled snails in our experiment; crabs crushed nearly all of the thin-shelled snails offered in both temperature treatments (Fig. 3). Instead, our results suggest that the influence of temperature on crushing performance varied with prey resistance to breakage. If this is the case, then both biomechanical and behavioral considerations may be important. For example, temperature could have affected muscle performance (Blundon 1989) so that crabs at the low temperature were unable to exert forces necessary to crush thickshelled prey. Alternatively, crabs might have avoided or limited the extent of their attacks on prey that are better defended if the risk or costs of claw damage (Juanes \& Hartwick 1990) were greater in colder water. Because calcium carbonate is under-saturated and more soluble in cold water (Vermeij 1993), 
exoskeletons could potentially be weaker and at greater risk of damage at low temperature. Additionally, performance costs associated with claw damage (Juanes \& Hartwick 1990) will take longer to overcome in colder water because molting rates are slower and, thus, recovery times longer. The question remains as to whether temperature constraints on plasticity are specific to warmer water species (including invaders) as they approach the lower limit of their temperature tolerance or also apply to crab species adapted to cold water.

Water temperature influenced absolute as well as relative claw size and, through its effects on molting rate, the predator's opportunity for trophic response. Carcinus maenas reared at the low temperature generated $\sim 6 \%$ larger carapace widths and larger absolute crusher claw sizes at the molt than did crabs at the high temperature. Crabs reared at the low temperature, however, took $34 \%$ longer to molt than did crabs at the high temperature (Fig. 4). This trade-off between molt increment and duration of the intermolt period is common in crustaceans. As shown in this and other experiments, the relative gain in absolute body size per molt at the low temperature fails to compensate for the delay in molting, so that the net effect of lowering temperature is to slow growth rate (Hartnoll 2001). Extrapolating from our results, C. maenas in colder water would molt twice in the time span in which crabs in warm water would molt 3 times. As a consequence, crabs in cold waters will possess claws that are absolutely, as well as relatively, smaller in size than their warm water counterparts over a similar time interval. Crabs with longer molt intervals are also at a disadvantage in terms of plasticity because longer intervals limit the opportunity for the exoskeleton to be remodeled in response to environmental heterogeneity.

Crabs raised on thick-shelled snails took significantly longer to molt than did those fed thin-shelled snails at both temperatures (Fig. 4B), which suggests a potential energetic cost if diet is limited to better defended prey. A delay might be expected given that Carcinus maenas consumed less snail flesh per day on the thick-shelled diet compared with the thin-shelled diet. Mohamedeen \& Hartnoll (1989) found that reduced amounts of food both prolonged the intermolt period and decreased molt increment; however, diet did not affect the molt increment in our experiment. Perhaps supplementation of the snail diet with mussel flesh 4.5 mo into the experiment erased differences in body size increase that might otherwise have been observed. Regardless, the mussel supplement did not affect trophic morphology; we detected no differences in claw size response in the subsets of crabs that molted before versus after mussel supplementation.
Phenotypic plasticity is often cited as characteristic of a good invader because it permits greater ecological flexibility (Richards et al. 2006) or 'buys' time (Schlichting 2004) for the invader to integrate and adapt evolutionarily to its new surroundings. For an invasive predator, modifications in trophic morphology are adaptive if they are in response to a directional change in prey resistance, improve foraging effectiveness and are, to some extent, heritable (Travis 1994, Doughty \& Reznick 2004). In our experiment, crabs raised at the high temperature responded to better defended prey by developing crusher claws that were $\sim 6 \%$ greater in relative claw height than were those of similar sized crabs feeding on more vulnerable prey. The direction and magnitude of this response should provide a fitness benefit in terms of foraging. First, crabs with relatively larger claws can exert greater closing force and access a wider range of prey types and sizes (e.g. Juanes \& Hartwick 1990, Behrens Yamada \& Boulding 1998). Second, the use-induced changes generated in our experiment were comparable in magnitude to differences in relative crusher claw height (approximately $9 \%$ ) between southern and northern populations of Carcinus maenas in the Gulf of Maine (Smith 2004), and these geographic differences affect foraging performance. By offering crabs Littorina obtusata of increasing size, Smith (2004) demonstrated that the larger-clawed southern crabs crushed both thick- and thin-shelled snails up to a greater size than did the smaller-clawed northern crabs of similar carapace width (see also Rochette et al. 2007). Together, these findings suggest that trophic plasticity in C. maenas is adaptive.

Phenotypic plasticity has the potential to play an important role in biological invasions by affecting the strength or direction of ecological interactions between introduced and resident species. Demonstration of adaptive phenotypic plasticity in an introduced species, however, is only a first (albeit important) step. The phenotypic response must also be interpreted within the context of the biotic and abiotic environment (Miner et al. 2005). For example, the arrival of an introduced predator could trigger induced defenses by native prey that counter adaptive changes in trophic morphology of the invader. The potential for reciprocal phenotypic responses between predator and prey has been documented recently in ciliates (Kopp \& Tollrian 2003) and amphibians (Kishida et al. 2006). Our demonstration of diet-induced claw change in an introduced crab, together with numerous studies documenting induced defensive changes in shell thickness of native molluscs (e.g. Smith \& Jennings 2000, Trussell \& Smith 2000), suggest a similar possibility in an invaded marine system. If these responses escalate over a defined period, then an ecological arms race could result (Agrawal 2001). 
If ecophenotypic responses are a common outcome of biological introductions, then the extent or rate of induced change must be examined across relevant abiotic backgrounds as the invader expands its range. Our results suggest that outcomes of local arms races in the Gulf of Maine between Carcinus maenas and Littorina obtusata are temperature-dependent. In warmer southern waters, C. maenas and L. obtusata each appear capable of responding to the other's cues. There, crab densities are greater, making associated chemical cues stronger and less variable among sites, and L. obtusata are able to build and maintain their shells more easily at a higher temperature. Littorina obtusata populations have responded by developing uniformly thick shells (Trussell 2000, Trussell \& Smith 2000). Likewise, C. maenas can molt more often in warmer water, and their crusher claws have responded to consistently strong snail defenses by becoming relatively larger.

In the colder waters to the north, higher suspected costs of shell maintenance (Vermeij 1993) and high spatial variability in crab abundances (Baldridge 2006) have resulted in greater variability in shell thickness among populations of snails in the north compared with those in the south (Trussell 2000). In contrast, we expect claw morphology to show little, if any, response to variation in prey defenses in colder water because (1) thicker shelled snails in the north are sufficiently well defended to discourage crushing attempts by Carcinus maenas, (2) even the thickest-shelled snails in the north are not as thick as those in the south (L. D. Smith unpubl. data) and, thus, are incapable of eliciting a trophic response, or (3) colder temperatures lengthen the intermolt period of $C$. maenas and limit opportunities for morphological response within each growing season. Indeed, evidence from field censuses suggests an asymmetrical arms race in the northern Gulf of Maine. Baldridge (2006) observed positive spatial and temporal correlations between shell thicknesses of Littorina obtusata and abundances of C. maenas in the northern Gulf of Maine. In contrast, relative claw sizes of $C$. maenas did not differ among sites over the same time frame. Together, these data suggest that, while claw plasticity may have facilitated the expansion of the historical range of $C$. maenas into rocky intertidal habitats in the southern Gulf of Maine, the advantage was lost as C. maenas moved north into colder waters.

Our findings strongly suggest that the role of phenotypic plasticity in generating post-invasion temporal or spatial patterns may be underestimated. Ecological mechanisms often operate at a scale different from the scale of observation (Levin 1992). Given too coarse a scale of observation, a mechanism such as rapid directional selection may be used to explain post-invasion phenotypic patterns (Seeley 1986, Losos et al. 1997), when, in fact, phenotypic plasticity may be largely responsible (Losos et al. 2000, Trussell \& Smith 2000). After a single molt interval on a thick-shelled diet, we induced crabs from the northern Gulf of Maine to develop crusher claws comparable in relative size to those of crabs from the southern Gulf of Maine (Fig. 5). Geographic differences in relative claw size, then, may be better explained by induced responses than by genetic differentiation and local adaptation, particularly given the ability of Carcinus maenas to disperse (Behrens Yamada 2001). In considering whether phenotypic shifts in post-invasion populations represent adaptive evolutionary change, ideally one would tease apart the relative contributions of genetic, environmental and genetic $\times$ environmental effects experimentally and test for fitness benefits over a range of relevant environments (Miner et al. 2005). Repeated invasions by C. maenas worldwide provide opportunities to test the potential for plasticity to generate phenotypic patterns within and among invasion sites.

Finally, climate change will influence biological invasions in terrestrial and aquatic environments in complex ways in the coming decades (Mooney \& Hobbs 2000). Indeed, these 2 serious environmental threats, climate change and the spread of exotic species, are inextricably linked. The strong effect of temperature on phenotypic plasticity of a fitness-related trait suggests that climate change will extend the range limits and ecological effect of introduced predators adapted to warm water.

Acknowledgements. We thank E. Callaghan, C. Masek, A. Whiting and Y. Zhang for their assistance in the field and laboratory The manuscript benefited from comments by D. M. Lodge, P. M. Peckol and P. R. Sievert. Support for the project was provided by a Smith College Wilens Fellowship (A.K.B.) and the Smith College Faculty Development Fund (L.D.S.).

\section{LITERATURE CITED}

Abby-Kalio NJ, Warner GF (1984) Effects of two different feeding regimes on the chela closer muscles of the shore crab Carcinus maenas (L.). Mar Behav Physiol 11:209-218

Agrawal AA (2001) Phenotypic plasticity in the interactions and evolution of species. Science 294:321-326

Baldridge AK (2006) The role of phenotypic plasticity in the interaction between an invasive crab predator, Carcinus maenas, and its native snail prey, Littorina obtusata. MA thesis, Smith College, Northampton, MA

Behrens Yamada S (2001) Global invader: the European green crab. Oregon State University Press, Corvallis, OR

Behrens Yamada S, Boulding EG (1998) Claw morphology, prey size selection and foraging efficiency in generalist and specialist shell-breaking crabs. J Exp Mar Biol Ecol 220:191-211

Bernays EA (1986) Diet-induced head allometry among foliage-chewing insects and its importance for graminivores. Science 231:495-497 
Blundon JA (1989) Effects of temperature and thermal history on neuromuscular properties of two crustacean species. J Comp Physiol B 158:689-696

Carlton JT, Cohen AN (2003) Episodic global dispersal in shallow water marine organisms: the case history of the European shore crabs Carcinus maenas and Carcinus aestuarii. J Biogeogr 30:1809-1820

Conover DO, Schultz ET (1995) Phenotypic similarity and the evolutionary significance of countergradient variation. Trends Ecol Evol 10:248-252

Doughty P, Reznick DN (2004) Patterns and analysis of adaptive phenotypic plasticity in animals. In: DeWitt TJ, Scheiner SM (eds) Phenotypic plasticity: functional and conceptual approaches. Oxford University Press, New York, p 126-150

Edgell TC, Rochette R (2007) Geographic correlation between reciprocally adaptive traits of an exotic decapod predator and native gastropod prey: evidence of an arms race? Evol Ecol Res 9:579-597

Elner RW (1980) The influence of temperature, sex and chela size in the foraging strategy of the shore crab, Carcinus maenas (L.). Mar Behav Physiol 7:15-24

$>$ Grosholz ED, Ruiz GM (1996) Predicting the impact of introduced marine species: lessons from the multiple invasions of the European green crab Carcinus maenas. Biol Conserv 78:59-66

Hartnoll RG (2001) Growth in Crustacea-twenty years on. Hydrobiologia 449:111-122

Hughes R, Elner RW (1979) Tactics of a predator, Carcinus maenas, and morphological responses of the prey, Nucella lapillus. J Anim Ecol 48:65-78

$>$ Juanes F, Hartwick EB (1990) Prey size selection in Dungeness crabs: the effect of claw damage. Ecology 71:744-758

Kishida O, Mizuta Y, Nishimura K (2006) Reciprocal phenotypic plasticity in a predator-prey interaction between larval amphibians. Ecology 87:1599-1604

Kopp M, Tollrian R (2003) Reciprocal phenotypic plasticity in a predator-prey system: inducible offences against inducible defenses? Ecol Lett 6:742-748

Lee SY (1993) Chela height is an acceptable indicator of chela strength in Carcinus maenas (Linnaeus, 1758) (Decapoda, Brachyura). Crustaceana 65:115-116

Levin SA (1992) The problem and pattern of scale in ecology. Ecology 73:1943-1967

Losos JB, Warheit KI, Schoener TW (1997) Adaptive differentiation following experimental island colonization in Anolis lizards. Nature 387:70-73

Losos JB, Creer DA, Glossip D, Goellner R and others (2000) Evolutionary implications of phenotypic plasticity in the hindlimb of the lizard Anolis sagrei. Evolution 54:301-305

Miner BG, Sultan SE, Morgan SG, Padilla DK, Relyea RA (2005) Ecological consequences of phenotypic plasticity. Trends Ecol Evol 20:685-692

Mitchell SC, Kennedy SM, Williams PJ, DeMont ME (2003) Morphometrics and estimates of force generation by the chelae of a North American population of the invasive green crab, Carcinus maenas (L.). Can J Zool 81:203-215

Mohamedeen H, Hartnoll RG (1989) The effect of variation in temperature and food supply on the growth of post-larval Carcinus maenas. In: Klekowski RZ, Styczynska-Jurewicz

Editorial responsibility: Roger Hughes,

Bangor, UK
E, Falkowski L (eds) Proc 21st Eur Mar Biol Symp. Polish Academy of Sciences, Wroclaw, p 115-122

> Moody KE, Steneck RS (1993) Mechanisms of predation among large decapod crustaceans of the Gulf of Maine coast: functional vs. phylogenetic patterns. J Exp Mar Biol Ecol 168:111-124

Mooney HA, Hobbs RJ (2000) Invasive species in a changing world. Island Press, Washington, DC

Petry AC, Agostinho AA, Piana PA, Gomes LC (2007) Effects of temperature on prey consumption and growth in mass of juvenile trahira Hoplias aff. malabaricus (Bloch, 1794). J Fish Biol 70:1855-1864

Richards CL, Bossdorf O, Muth NZ, Gurevitch J, Pigliucci M (2006) Jack of all trades, master of some? On the role of phenotypic plasticity in plant invasions. Ecol Lett 9: 981-993

Robinson BW, Parsons KJ (2002) Changing times, spaces, and faces: tests and implication of adaptive morphological plasticity in the fishes of northern postglacial lakes. Can J Fish Aquat Sci 59:1819-1833

> Rochette R, Doyle SP, Edgell TC (2007) Interaction between an invasive decapod and a native gastropod: predator foraging tactics and prey architectural defenses. Mar Ecol Prog Ser 330:179-188

> Schenk SC, Wainwright P (2001) Dimorphism and the functional basis of claw strength in six brachyuran crabs. J Zool 255:105-119

Schlichting CD (2004) The role of phenotypic plasticity in diversification. In: DeWitt TJ, Scheiner SM (eds) Phenotypic plasticity: functional and conceptual approaches. Oxford University Press, New York, p 191-200

Seeley RH (1986) Intense natural selection caused a rapid morphological transition in a living marine snail. Proc Natl Acad Sci USA 83:6897-6901

Smith LD (2004) Biogeographic differences in claw size and performance in an introduced crab predator Carcinus maenas. Mar Ecol Prog Ser 276:209-222

Smith LD, Jennings JA (2000) Induced defensive responses by the bivalve Mytilus edulis to predators with different attack modes. Mar Biol 136:461-469

Smith LD, Palmer A (1994) Effects of manipulated diet on size and performance of brachyuran crab claws. Science 264 : $710-712$

Taylor GM (2000) Maximum force production: why are crabs so strong? Proc R Soc Lond B Biol Sci 267:1475-1480

Travis J (1994) Evaluating the adaptive role of morphological plasticity. In: Wainwright PC, Reilly SM (eds) Ecological morphology: integrative organismal biology. University of Chicago Press, Chicago, IL, p 99-122

Trussell GC (2000) Phenotypic clines, plasticity, and morphological trade-offs in an intertidal snail. Evolution 54: 151-166

> Trussell GC, Smith LD (2000) Induced defenses in response to an invading crab predator: an explanation of historical and geographic phenotypic change. Proc Natl Acad Sci USA 97:2123-2127

Vermeij GJ (1993) A natural history of shells. Princeton University Press, Princeton, NJ

Wallace JC (1973) Feeding, starvation and metabolic rate in the shore crab Carcinus maenas. Mar Biol 20:277-281

Submitted: November 12, 2007; Accepted: March 13, 2008 Proofs received from author(s): July 24, 2008 